\title{
EDUCAÇÃO SUPERIOR INDÍGENA: ANÁLISE DO DISCURSO DO INDÍGENA SOBRE O PAPEL DO PROFESSOR NÃO INDÍGENA NA SUA FORMAÇÃO ACADÊMICA
}

\author{
INDIGENOUS MAJOR EDUCATION: \\ ANALYSIS OF INDIGENOUS DISCOURSE ON THE ROLE OF NON-INDIGENOUS \\ TEACHERS IN THEIR ACADEMIC FORMATION \\ EDUCACIÓN SUPERIOR INDÍGENA: \\ ANÁLISIS DEL DISCURSO DEL INDÍGENA SOBRE EL PAPEL DEL PROFESOR NO \\ INDÍGENA EN SU FORMACIÓN ACADÉMICA
}

Messias Furtado Silva ${ }^{1}$, Odete Pacubi Baierl Teixeira ${ }^{2}$

\section{RESUMO}

Neste artigo mobilizamos recursos de análise do discurso para investigar como indígenas de dois povos (Gavião e Surui Aikewara) percebem o papel do professor não indígena em sua formação acadêmica, visando compreender como estes veem a intervenção do professor, formado em outra cultura, com jeito de ser e viver diferente, em sua cultura. Analisamos, a partir de uma questão geradora, como o indígena percebe a relação indígena-não indígena na formação do professor indígena. Os resultados evidenciam o quanto o indígena valoriza a interculturalidade pautada no respeito e reconhecimento dos saberes de cada povo.

PALAVRAS-CHAVE: Interculturalidade. Educação indígena. Formação de professores.

\section{ABSTRACT}

In this article, we mobilized discourse analysis resources to analyze how indigenous people from two ethnic groups (Gavião and Surui Aikewara) perceive the role of the non-indigenous teacher in their academic formation, aiming to understand how they see the teacher's intervention, which was formed in another culture, with a different way of being and living, in their culture. We investigated, from a generating question, how the indigenous perceives the relation indigenous/non-indigenous in the formation of the indigenous teacher. The results show how much the indigenous values the interculturality based on respect and recognition of each people's knowledge.

KEYWORDS: Interculturality. Indigenous education. Teacher formation.

\section{RESUMEN}

En este articulo mobilizamos recursos de análisis del discurso para analisar cómo indígenas de dos pueblos (Gavião y Surui Aikewara) perciben el papel del profesor no indígena en su formación académica, buscando la comprensión de cómo estos ven la interverción del profesor, formado em otra cultura, con forma de ser y vivir diferente, en su cultura. Investigamos, a partir de una cuestión generadora, cómo el indígena percibe la relación indígena no indígena en la formación del profesor indígena. Los resutados evidencian cuanto el indígena valora la interculturalidad pautada en el respeto y reconocimiento de los saberes de cada Pueblo.

PALABRAS CLAVES: Interculturalidad; Educación indígena; formación de profesores.

\footnotetext{
${ }^{1}$ Doutorando em Educação para a Ciência - Universidade Estadual Paulista. Faculdade de Ciências. (UNESP/Bauru) - Bauru, SP - Brasil. Professor de Licenciatura Intercultural Indígena - Universidade do Estado do Pará (UEPA) - Pedreira, Belém, PA - Brasil. E-mail: messias.silva@fc.unesp.br

2 Doutora em Educação - Universidade de São Paulo (USP) - São Paulo, SP - Brasil. São Paulo, SP - Brasil.

Professora - Programa de Pós-Graduação em Educação para a Ciência - Universidade Estadual Paulista (UNESP/Bauru) - Bauru, SP - Brasil. E-mail: opbt@gmail.com
}

Submetido em: 08/08/2017 - Aceito em: 24/05/2018

(C) ETD-Educação Temática Digital Campinas, SP

v.20 n.4

p. $1036-1058$ out./dez. 2018 


\section{INTRODUÇÃO}

Os povos indígenas do Brasil, desde a promulgação da Carta Constitucional de 1988 (CRFB/88), que reconhece aos indígenas: sua organização social envolvendo costumes, línguas, crenças e tradições; direito sobre as terras que tradicionalmente ocupam; direito a educação escolar diferenciada e bilingue, prioritariamente feita pelos indígenas e para os indígenas; direito de utilizarem suas línguas maternas e processos próprios de aprendizagem no ensino fundamental; e, garantia do pleno exercício dos direitos culturais e acesso às fontes da cultura nacional, lutam pela efetivação dos direitos nela previstos. $A$ CRFB/88 também obriga o Estado Brasileiro a proteger as manifestações culturais dos indígenas e de outros grupos participantes do processo civilizatório nacional. A afirmação de direitos aos povos indígenas na $\mathrm{CRFB} / 88$ é delineadora da concepção de estado multicultural e pluriétnico, de convivência respeitosa com a diferença.

No plano legal, tais direitos foram reafirmados na Lei de Diretrizes e Bases da Educação Nacional (LDBEN), ao dispor que o objetivo da educação escolar indígena é proporcionar aos povos indígenas a recuperação de suas memórias históricas, bem como a reafirmação de suas identidades étnicas e valorização de suas línguas e ciências, garantindo a estes e suas comunidades o acesso às informações, conhecimentos técnicos e científicos da sociedade nacional e demais sociedades indígenas e não indígenas.

No plano normativo, o Referencial Curricular Nacional para a Educação Escolar Indígena (RCNEI, 1998) estabelece que aos povos indígenas, a educação deve assentar-se em princípios que lhes são próprios, dentre os quais a formação de crianças e jovens como processo integrado, visto que uma característica comum às sociedades indígenas é que cada experiência cognitiva e afetiva carrega múltiplos significados. 


\section{EDUCAÇÃO ESCOLAR INDÍGENA: O DIREITO À ESCOLA CIDADÃ}

O RCNEI (1998) pugna para que a educação escolar indígena deva ser, progressivamente, assumida pelos indígenas em seu movimento pela autonomia, oferecendo uma escola diferenciada, que ofereça Educação Intercultural e Bilíngue (EIB) ${ }^{3}$, com o propósito de: reconhecer e manter a diversidade cultural e linguística; promover uma situação de comunicação entre experiências socioculturais, linguísticas e históricas diferentes, não considerando uma cultura superior à outra; estimular o entendimento e o respeito entre seres humanos de identidades étnicas diferentes, reconhecendo que tais relações vêm ocorrendo historicamente em contextos de desigualdade social e política.

Sob essa perspectiva, a escola indígena é o lugar onde a relação entre os conhecimentos próprios e os conhecimentos das demais culturas deve se articular, constituindo uma possibilidade de formação e divulgação para a sociedade nacional de saberes e valores importantes até então desconhecidos desta.

O RCNEI reconhece que efetivar esse modelo de escola esbarra em três problemas: O primeiro é que a maioria dos professores indígenas não passou pela formação em magistério, grande parte deles domina conhecimentos próprios da sua cultura, mas tem precário conhecimento da língua portuguesa e das demais áreas dos conteúdos considerados escolares. O segundo é que os professores não-indígenas que atuam nas escolas indígenas, mesmo quando têm o curso de magistério, não possuem conhecimentos sobre os povos indígenas, provocando, distorções no processo ou impedindo o desenvolvimento da proposta de educação intercultural. O terceiro é a dificuldade de acesso a informações adequadas sobre os povos indígenas, pois a divulgação fora do círculo dos pesquisadores e especialistas é ainda deficitária, dificultando a plena compreensão do que seja a educação escolar indígena.

\footnotetext{
${ }^{3}$ A EIB, segundo o modelo pugnado pelo RCNEI, não é consenso. Os Wai-Wai da aldeia Mapuera adotam o modelo que reforça o contato do indígena com a língua Wai-Wai da família Karib (CANCIO, 2017, COELHO E SILVA, 2018) e o ensino nas séries iniciais é feito todo em língua materna e a introdução da língua portuguesa só acontece no 60 ano. Paladino (2006) relata a experiencia entre os Ticuna, em que mesmo na escola da aldeia o indígena quer acesso "ao conhecimento do branco" para melhorar de vida, muitos dos jovens, inclusive, saem da aldeia para estudar nas escolas das cidades. Luciano (2011) observou entre os povos indígenas do Alto Rio Negro três tendências, a primeira baseada na ideia de que a escola indígena deve ter como objetivo principal o fortalecimento das identidades e culturas indígenas; a segunda baseada no entendimento de que a escola indígena deve priorizar o acesso aos conhecimentos científicos e técnicos do mundo moderno. A terceira, que considera a escola como espaço de articulação, no mesmo nível, das duas perspectivas, ou seja, que a escola indígena valorize e trabalhe ao mesmo tempo tanto os conhecimentos tradicionais dos povos indígenas quanto os conhecimentos científicos e técnicos do mundo moderno.
} 
O Movimento Indígena (MI) tem reafirmado a ideia de que a educação escolar indígena, para ser realmente específica e diferenciada, necessita que os profissionais que atuam nas escolas pertençam às sociedades envolvidas no processo escolar. Assim, segundo - MI, a garantia de acesso ao conhecimento de outras sociedades indígenas e, em particular, de sociedades não indígenas, só poderia fazer-se por meio da educação formal, em cursos de formação de professores indígenas. Desta maneira, a formação superior, especialmente os cursos de formações de professores indígenas, deveriam ter por base a interculturalidade.

\title{
3 FORMAÇÃO DE PROFESSORES INDÍGENAS: LICENCIATURA INTERCULTURAL DA UEPA.
}

Uma das frentes de luta visando oportunizar cursos de formação de professores para povos indígenas envolve acionar o Estado e os órgãos de proteção jurídica aos indígenas, em especial o Ministério Público (MP), para intermediar contatos junto as agencias formadoras no oferecimento dos referidos cursos. Fruto de uma dessas intermediações, em 2012 a Universidade do Estado do Pará (UEPA) inicia o Curso de Licenciatura Intercultural Indígena a três turmas dos povos Gavião, Surui Aikewara e Tembé, no qual um dos autores do presente artigo, atuou como professor de duas disciplinas: "Prática como Componente Curricular e Orientação de Trabalho de Conclusão de Curso".

A filosofia norteadora do Curso é a interculturalidade a partir dos referenciais curriculares para a educação escolar indígena e para formação de professores indígenas. 0 processo formativo promove situações de comunicação entre diferentes experiências socioculturais, linguísticas e históricas sem interpor relação de superioridade entre uma cultura e outra.

\begin{abstract}
A interculturalidade orienta processos que têm como base o reconhecimento do direito à diferença e a luta contra todas as formas de discriminação e desigualdade social. Tenta promover relações dialógicas e igualitárias entre pessoas e grupos que pertencem a universos culturais diferentes, trabalhando conflitos inerentes a esta realidade. Não ignora as relações de poder presentes nas relações sociais e interpessoais. Reconhece e assume conflitos procurando as estratégias mais adequadas para enfrentá-los. (CANDAU, 2002, p. 19)
\end{abstract}

Respeitando o princípio de autonomia dos indígenas na gestão dos processos educacionais, o curso se desenvolve apenas com povos que o solicitam, sendo que o currículo e as práticas são dimensionados sob consulta aos povos que serão atendidos.

Os participantes das turmas acima referidas concluíram o Curso e iniciaram em 2017 formação continuada no Curso de Especialização em Docência em Educação Escolar Indígena. Nestes cursos a maioria dos professores não são indígenas, mas tem longo processo de convivência com os indígenas, ministrando disciplinas, coordenando projetos 
de práticas integradas, elaborando e orientando projetos de pesquisa e Trabalhos de Conclusão de Curso e diversas outras atividades referentes aos Cursos.

Este artigo é fruto de paragem reflexiva no intuito de conhecer o que pensa o indígena sobre o papel do professor não indígena em sua formação. Investigamos a relação indígena-não indígena via discurso dos indígenas. O pressuposto desta pesquisa é que a interação indígena-não indígena favorece aos primeiros o acesso às informações, conhecimentos técnicos e científicos da sociedade nacional recomendados pela LDBEN e, aos segundos, o acesso a diferentes formas de ser e viver, importantes ao entendimento da realidade brasileira.

\section{METODOLOGIA}

Esta pesquisa, com contornos qualitativos, mobilizou recursos de Análise do Discurso (AD) para analisar os discursos produzidos por graduados do Curso de Licenciatura Intercultural Indígena. $O$ estudo foi realizado um ano após a conclusão do referido Curso, por isso a necessidade de se buscar na memória dos participantes a resposta para nossa questão de pesquisa.

Achard (1999) menciona que para haver memória é preciso que o acontecimento ou o saber registrado saia da indiferença, que deixe o domínio da insignificância, e conserve força a fim de poder posteriormente fazer impressão. Lembrar um acontecimento ou um saber não é forçosamente mobilizar e fazer jogar uma memória social. Há necessidade que o acontecimento lembrado reencontre sua vivacidade e, sobretudo, é preciso que ele seja reconstruído a partir de dados e de noções comuns aos diferentes membros da comunidade.

A pesquisa buscou nos indígenas sua percepção sobre o papel do professor não indígena em sua formação, que vai além do diploma recebido. Os dados foram obtidos a partir de entrevista semiestruturada, com questão geradora única: o que você pensa sobre o papel do professor não indígena em sua formação acadêmica?

$\mathrm{Na}$ análise dos dados utilizamos pressupostos de AD defendidos por Pêcheux (1999, 2014) e Orlandi (1999, 2001, 2005), evidenciando as condições de produção do discurso e lançando luz sobre o papel do não indígena na formação acadêmica do indígena vista pelos olhos dos próprios indígenas. A condição de produção de um discurso é importante porque influencia tanto na forma e na escolha "do quê" e "como" falamos em determinada condição ou situação, assim materialidade simbólica e materialidade histórica se entrelaçam. Concluída a análise, devolvemos o artigo aos indígenas participantes para lhes dar conhecimento de como suas falas foram utilizadas. Após a leitura, os participantes assinaram Termo de Cessão (TC) de uso das falas, nos autorizando a publicação. 


\section{AS CONDIÇÕES DE PRODUÇÃO: POVOS PARTICIPANTES.}

Participaram desta pesquisa 13 indígenas, 05 do povo Surui Aikewara, habitantes da Terra Indígena Sororó, e 08 do povo Gavião, habitantes da Terra Indígena Mãe Maria. Salientamos que para Pêcheux (2014), um discurso é sempre proferido a partir de condições de produção dadas, de um certo lugar no interior de uma formação dada, assim optamos por descrever de que lugar falam nossos Participantes, e em que condições se originou os discursos.

Segundo SURUÍ, (2016) a Terra Indígena Sororó está localizada no sudeste do Pará, as margens da BR153. O povo Aikewara, também conhecida como Suruí do Pará habitam a terra indígena Sororó e possui uma população de aproximadamente 400 habitantes. Atualmente, por necessidade de vigiar sua terra, estão divididos nas aldeias Sororó, Ytahi, Yeta, Tykapehi, Ipirahiete e Awusehe, localizadas em locais estratégicos. A Terra Indígena Sororó está localizada entre quatro municípios da região sudeste do Pará (Marabá, São Domingos do Araguaia, São Geraldo do Araguaia e Brejo Grande do Araguaia). As aldeias Sororó e Yeta são responsabilidade do município de Brejo Grande do Araguaia, as Aldeia ytahi, tykapehi, Ipirahiete são responsabilidade do município de São Geraldo do Araguaia e a aldeia Awusehe não tem ainda município definido.

O povo Gavião habita a Terra Indígena (TI) Mãe Maria, localizada entre os municípios de Marabá e Bom Jesus do Tocantins no Estado do Pará. A TI é dividida em 16 aldeias. Segundo Rikparti (2016), três são os povos indígenas que residem no Território Indígena Mãe Maria: os Akrãtikatêjê, os Parkatêjê e os Kýikatêjê. Esses três povos são conhecidos como Gavião, nome dado pelos kupẽ ${ }^{4}$, porque usavam penas do pássaro gavião em suas flechas e nos adornos, e também por serem valentes.

Segundo dados do Instituto Sócio Ambiental (ISA, 2015), na primeira metade do século XX, o povo Gavião se distribuiu em três grupos autodenominadas conforme a posição que ocuparam na bacia do rio Tocantins. Um chamou-se Parkatêjê (onde par é pé, jusante; katê é dono; e jê é povo), "o povo da jusante", outro se chamou Kýikatêjê (onde kyi é cabeça), "o povo da montante", pois devido a guerra entre as duas, a primeira refugiou-se a montante do rio Tocantins, já no Estado do Maranhão. Por essa razão os Kýikatêjê são também designados como "grupo do Maranhão". O terceiro grupo ficou conhecida como "turma da Montanha" conforme sua autodenominação Akrãtikatêjê (onde akrãti é montanha), ocupava as cabeceiras do rio Capim.

\footnotetext{
${ }^{4}$ Não indígena para os povos da Terra Indígena Mãe Maria
} 


\title{
6 AS CONDIÇÕES DE PRODUÇÃO: A LÍNGUA DOS POVOS PARTICIPANTES.
}

Pêcheux (1997) considera que o sistema da língua é o mesmo para o materialista e para o idealista, para o revolucionário e para o reacionário, para aquele que dispõe de um conhecimento dado e para aquele que não dispõe desse conhecimento. Entretanto, não se pode concluir, a partir disso, que esses diversos personagens tenham o mesmo discurso, pois a língua se apresenta como a base comum de processos discursivos diferentes, empreendidos nela na medida em que os processos ideológicos simulam processos científicos.

Os Aikewara falam em língua portuguesa e em língua Tupi-Guarani. A língua TupiGuarani faz parte do tronco linguístico Tupi, que comporta, além desta, o Arikem, Aweti, Juruna, Mawé, Monde, Puruborá, Mundurucu, Ramarama e Tupari. Os Gavião falam em língua portuguesa e em língua Jê-Timbira. A língua Jê-Timbira faz parte do tronco linguístico Macro-Jê, que comporta, além da língua Jê, o Bororo, Krenak, Guató, Karajá, Maxakali, Ofayé, Rikbaktsa e Yaté. A língua, segundo Saussure (2006), nada mais é que o conjunto dos costumes linguísticos que permitem a um sujeito se comunicar. As línguas indígenas que apresentam alto grau de semelhanças são agrupadas em troncos linguísticos.

\begin{abstract}
As línguas são classificadas em famílias de acordo com critérios genéticos: se situam em uma mesma família de línguas para as quais há evidência científica de que derivam, por evolução a longo do tempo, de uma mesma língua no passado mais ou menos remoto, mantendo um determinado nível de afinidade em sua gramática e em seu léxico. Existem famílias que revelam uma afinidade genética mais distante no tempo e constituem uma unidade mais ampla, que chamamos troncos linguísticos. No Brasil reconhecem-se 42 famílias linguísticas genéticas, dez das quais constituem o tronco Tupí e outras doze que integram o tronco Macro-Jê. (RODRIGUES, 2013, p. 11)
\end{abstract}

Para Luciano (2006), apesar de muitas línguas indígenas terem sido extintas desde a colonização, os povos indígenas do Brasil ainda conservam e falam mais de 180 línguas nativas. Embora a língua não seja o principal elemento que identifica um povo indígena, ela é um fator importante de produção e reprodução dos conhecimentos tradicionais e de incorporação, de forma apropriada, dos novos conhecimentos do mundo externo ao grupo.

Uma das formas usadas pelo colonizador português para tentar exterminar os indígenas foi proibindo-os de falar suas línguas de origem e adoção da língua portuguesa como língua única. Luciano (2006), analisando diversos estudos da área linguística, calcula que existiam no Brasil à época do "descobrimento" entre 1200 a 1500 línguas indígenas. Destas, as que ainda existem são fruto de resiliência, de resistência as tentativas de obrigálos a abandonar sua língua. O próprio Luciano, que é Baniwa, relata experiência vivida na escola-internato, onde diversos castigos eram ministrados aos indígenas que pronunciavam 
sua língua materna, dentre os quais, ficar com um pedaço de corda envolta do pescoço, que segurava um pedaço de madeira com a inscrição: "Eu não sei falar português".

\section{AS CONDIÇÕES DE PRODUÇÃO: O PROCESSO DE FORMAÇÃO DOS PARTICIPANTES E A INTERVENÇÃO DO NÃO-INDÍGENA}

A educação do indígena antes da chegada do colonizador tinha por característica ser integral, à medida que todos aprendiam tudo o que tinha para se aprender na aldeia, de forma espontânea, sendo que os ensinamentos eram práticos, e os conhecimentos transmitidos sob a forma, aproximando-se daquilo que Ponce (2015) chamou de educação utilitarista e coletiva, visto não haver nada que estivesse acima dos interesses e necessidades das aldeias.

Dados da Secretaria de Educação Continuada, alfabetização e Diversidade (SECAD, 2007) mostram que em 1500, o Brasil era habitado por aproximadamente 10 milhões de indígenas, distribuídos em diferentes grupos étnicos, com costumes e tradições próprias e falantes de aproximadamente 1200 diferentes línguas. A "educação para" indígenas começa a se estruturar a partir de 1549, com a chegada da primeira missão jesuítica, composta por missionários da Companhia de Jesus e chefiada pelo padre Manuel da Nóbrega, a missão tinha como um dos objetivos converter os nativos à fé cristã. Luciano (2011) afirma que a trajetória da educação escolar indígena até a década de 1970 foi marcada por profundo desrespeito aos saberes indígenas e funcionou como tentativa de dizimação dos indígenas pelo forçoso processo de embranquecimento cultural.

Nessa trajetória identificamos o modelo missionário, fruto da aliança do colonizador português com a Companhia de Jesus, caracterizado pela predominância da catequese, com o objetivo de inserir os indígenas na fé cristã. Este período tem o selo das grandes proibições, como a prática do xamanismo e dos rituais, na tentativa de impedir que o indígena desenvolvesse sua cultura. As marcas desse período são a repressão; as grandes matanças de indígenas; a tentativa de impor a estes uma cultura exterior trazida de uma terra distante; e a resistência do indígena em se curvar diante do colonizador.

A resistência do indígena e a ressignificação dos rituais e práticas culturais levaram a implantação, ainda na aliança colonizador-igreja, de um segundo modelo, o internato, na qual a criança indígena era retirada do convívio de seu grupo, colocada em um ambiente hostil, onde os castigos eram pesados, sendo proibido de pronunciar sua língua e manifestar sua cultura. Qualquer tentativa de se contrapor as regras era severamente punida.

O objetivo do internato era afastar as novas gerações da cultura de seu povo, com a intenção de, à medida em que os indígenas mais velhos fossem morrendo, efetivar o processo de embranquecimento do indígena. Bergamaschi (2005) salienta que, desde então, 
os processos educacionais próprios da tradição de cada povo indígena foram rechaçados, empurrados para o subterrâneo, a fim de dar lugar a uma compreensão de educação que se reduzia a catequese e a educação escolar.

A ação missionária foi, com certeza, a iniciativa mais antiga e contundente para educar o nativo e, entre outras práticas que visavam a europeização e a cristianização da América. Na visão do missionário, o indígena, com seus rituais, formas de vestir, xamanismo, era, usando termo de Bauman (1998) "um estranho", não se encaixava no mapa cognitivo, moral ou estético do mundo "civilizado" europeu e sua simples presença deixava turvo o que devia ser transparente e confuso o que devia ser coerente.

O começo do século XX é marcado pelo advento das ideias positivistas e tentativa de "modernização" do Brasil. Inicia a mudança na base econômica essencialmente agrária para um princípio de industrialização. Na visão dos dominantes, o indígena era um empecilho a essa modernização, considerado como desordeiro, sujo e preguiçoso. $O$ estranho que deve ser "incorporado" ao desenvolvimento. Para essa incorporação, foi criado o Serviço de Proteção ao Índio (SPI), com o objetivo de "integrar" os indígenas a "sociedade nacional", domesticá-los e transformá-los em empregados para um país que "queria ser grande". Intensifica-se o processo de escolarização do indígena em duas frentes: escola pública regular; e financiamento de "missões religiosas" para ensinar os indígenas, como relata Kopenawa (2015) sobre o trabalho da New Tribes Mission entre os povos Yanomami.

É na década de 1970 que o MI organizado começa a se fortalecer e lutar por educação diferenciada que fortaleça a cultura e tradição dos povos, reconhecendo a necessidade do acesso do indígena a escolarização, face as mudanças em sua dinâmica de vida e contato com os não indígenas. Com este reconhecimento passam a exigir Eeducação Escolar Intercultural, Bilíngue e Diferenciada (EIB). Educação para a cidadania do indígena. Como menciona PALADINO \& ALMEIDA (2012, p.16).

O conceito de interculturalidade traz a ideia de inter-relação, dialogo e troca entre culturas diferentes e supõe a coexistência da diversidade como riqueza. Este conceito começou a ocupar um lugar importante nos debates sobre educação a partir da década de 1970, quando a diversidade étnica e cultural tornou-se fonte de preocupação por parte dos chamados países desenvolvidos, principalmente os europeus. Os governos de Espanha, Franca e Itália, por exemplo, incorporaram estas ideias em seus projetos de educação voltados aos imigrantes e a outras minorias presentes em seus territórios nacionais, como os ciganos.

Walsh (2008) acrescenta que a interculturalidade estimula um processo político e um projeto social voltado para a construção de novas e diferentes sociedades, relações e 
condições de vida. Os povos pesquisados se situam nessa premissa, que se traduz na busca de autonomia e do fim de qualquer forma de tutelamento.

A luta pela EIB ganhou forte impulso com a CRFB/1988, que elevou o orgulho do indígena de ser indígena. A LDBEN/1996 ratifica o direito a educação diferenciada e, no plano normativo, o RCNEl faz tomar força a ideia de construir um sistema próprio que dê sustentação a EIB. Candau e Russo (2010) indicam que esses movimentos nos colocam diante da realidade histórica do continente, marcada pela negação dos "outros", física ou simbólica, ainda presente nas sociedades latino-americanas.

Para implantar a escola diferenciada, os povos indígenas carecem de professores enraizados na cultura da aldeia e, por exigência legal, formados em cursos de licenciatura. Começa então a luta por educação superior intercultural, que respeite os saberes de cada povo e se entrelace com eles em processo dialógico, que Santos (2011) chama de ecologia de saberes. No Estado do Pará, para atender essa demanda, a UEPA cria o Curso de Licenciatura Intercultural Indígena, oferecido a princípio a três povos, dois dos quais participantes dessa investigação.

\section{ANÁLISE DO DISCURSO: CONSTITUIÇÃO E DISCUSSÃO DOS DADOS}

Nesta pesquisa nos ancoramos na teoria da análise do discurso (AD) para interpretar os discursos produzidos pelos participantes ao responderem a pergunta a qual foram submetidos. Orlandi (2001) infere que a AD não trata da língua ou da gramática, embora todas essas coisas lhe interessem. Trata do discurso e, a palavra discurso, etimologicamente, tem em si a ideia de curso, de percurso, de correr por, de movimento. O discurso é assim, palavra em movimento. No estudo do discurso observa-se o homem falando. $\mathrm{Na}$ análise de discurso, procura-se compreender a língua fazendo sentido, enquanto trabalho simbólico, parte do trabalho social geral, constitutivo do homem e da sua história. Por esse tipo de estudo se pode conhecer melhor aquilo que faz do homem um ser especial com sua capacidade de significar e significar-se.

Apoiados em Pêcheux (2014) e atentos as condições similares de produção do discurso pelo grupo, consideramos os discursos dos participantes como "representativos do conjunto dos discursos possíveis", sem, contudo, considera-los como simples elementos justapostos, pois tem entre si relações suscetíveis de variar segundo a natureza dos elementos colocados. Quando instados a manifestar opinião a respeito do papel do professor não indígena em sua formação, mesmo partindo de condições de produção que se assemelham, a forma como cada indivíduo vê o outro não prescinde de condições de produção intrapessoal, não analisadas neste artigo. 
Pêcheux e Fuchs (2014), esclarecem que a AD reside na articulação de três regiões do conhecimento cientifico: o materialismo histórico como teoria das formações sociais e suas transformações; a linguística como teoria dos mecanismos sintáticos e o processo de enunciação ao mesmo tempo; e a teoria do discurso, como teoria da determinação histórica dos processos semânticos que coloca em evidencia os traços do processo discursivo tomando como ponto de partida o corpus discursivo.

Orlandi (2001) avalia que para encontrar as regularidades da linguagem em sua produção, o analista do discurso relaciona a linguagem a sua exterioridade, considerando os processos e condições de produção da linguagem pela análise da relação estabelecida pela língua com os sujeitos que a falam e as situações em que se produz o dizer. Orlandi (2005) avalia que a prática de leitura proposta por Pêcheux, expõe o olhar leitor à materialidade do texto, objetivando a compreensão do que o sujeito diz em relação a outros dizeres.

Nesses fundamentos, os resultados foram agrupados nas seguintes dimensões: interculturalidade; construção de novos saberes; transmissão de saberes; crescimento pessoal e profissional. Na análise tratamos separadamente cada uma das dimensões, relacionando-a com as respostas emitidas pelos participantes. Utilizaremos a letra P para denotar participante, sendo: P1, P2, P3, P4 E P5 participantes do povo Surui Aikewara e P6, P7, P8, P9, P10, P11. P12 e P13 participantes do povo Gavião. No quadro abaixo apresentamos a disposição do discurso por participante dentro das dimensões analíticas.

Quadro 1. Disposição do discurso por participante segundo as categorias analíticas.

\begin{tabular}{|l|c|c|c|c|c|c|c|c|c|c|c|c|c|}
\hline Categoria analítica & \multicolumn{10}{|c|}{ Disposição do discurso } \\
\cline { 2 - 11 } & P1 & P2 & P3 & P4 & P5 & P6 & P7 & P8 & P9 & P10 & P11 & P12 & P13 \\
\hline 1. Interculturalidade & X & X & X & X & & & & & X & X & & X & X \\
\hline 2 Construção de novos saberes & X & & X & & & & & X & & & X & X & X \\
\hline 3. Transmissão de saberes & & X & & & X & X & & X & & & & & X \\
\hline 4. Crescimento pessoal e profissional & & & X & X & X & X & X & & X & X & X & & X \\
\hline
\end{tabular}

Fonte: Constituição dos dados pelos autores

\section{Dimensão 1. Interculturalidade}

Interculturalidade foi um aspecto que nos chamou atenção a medida que a maioria dos participantes mencionou esta Dimensão. (P1, P2, P3, P4, P9, P10 e P12). O próprio 
título do Curso ofertado aos participantes se consubstancia na ideia da não hierarquia entre saberes, que não há cultura superior. Existem culturas, e cada povo produz a sua, sendo próprio de uma sociedade pluriétnica e multicultural a convivência harmônica e dialógica entre as diferentes culturas que compõem a nação. Destacamos a seguir trechos dos discursos que nos levou a eleger esta Dimensão:

P1.A relação entre duas personalidades diferentes. Ao mesmo tempo nós aprendemos com o professor não indígena e eles também aprendem; P2.0 curso era intercultural e as experiências de professores não indígenas são essenciais e de grande relevância; P3.Com eles nós indígenas iremos aprofundar mais e mais em outra cultura; P4.Quando já estivermos formados, vejo que também precisamos destes profissionais atuando como professores na vida dos estudantes indígenas; P9.Somos indígenas, mas podemos ser grandes profissionais através deles, e buscar não só a formação, mas também a especialização; P10.Alguns professores conviveram mais tempo com a turma e com esses a amizade é maior, mais nada que interferisse no trabalho deles; P12.Eu não penso e nem acho, mais de fato é que o professor não indígena terá sempre um grande valor para mim e meu povo indígena, já que houve umas trocas de ensinar e aprender, nessa jornada de conhecimentos, experiencias, respeito e principalmente a paciência de trabalhar com os indígenas; P12.Então eu acredito que não foi só eu que ganhei com essa graduação e sim, também, o professor não indígena, porque ele teve o prazer de conhecer e conviver o cotidiano indígena dentro de uma aldeia que será lembrado sempre. P13.Sua participação nas janelas que minha mente vai abrindo a medida que vou adquirindo informações dos conhecimentos científicos ou até mesmo do empírico é a força impulsionadora que abre essas janelas.

\section{Dimensão 2: Construção de novos saberes}

Um dos objetivos do $\mathrm{Ml}$ é que o professor indígena tenha acesso e se empodere dos saberes da sociedade nacional de forma crítica para assim atuar na escola indígena. Este objetivo foi demonstrado pelos participantes P1, P3, P8, P11, P12 e P13. O discurso se referem ao compromisso em adquirir os saberes, como nos excertos abaixo:

P1.A presença de professores não indígenas no meio da formação da educação indígena será sempre uma forma de poder entender um pouco da história e até mesmo da realidade de cada aluno indígena; P3.Que ele possa entender as necessidades de um acadêmico indígena e as de seu povo, tanto na sua cultura como em história; P8.Os professores não indígenas não sabem sobre a nossa vida social e as nossas culturas tradicionais, pois os mesmos podiam se aprofundar mais em suas disciplinas; P11.0 papel do professor não indígena na formação acadêmica dos indígenas é muito bem aceito, pois os conhecimentos que esses professores têm a oferecer vem sempre tentar nos despertar para a realidade de um mundo cheio de preconceitos, onde podemos ser respeitados; P12.Agradeço muito os professores não indígenas por nos dar essa ferramenta de qualificação para trabalharmos e lutarmos em cima de nossas necessidades e principalmente cuidar e valorizar a cultura 
indígena. P13. Costumo compará-lo com um ancião que tem prazer em ver um jovem crescer com sabedoria, prudência e ganhando experiencia.

\section{Dimensão 3: Transmissão de saberes}

Para construir uma formação indígena de qualidade é necessário que o professor não indígena cumpra sua função de transmitir criticamente as informações que produzam conhecimentos. $\mathrm{O}$ indígena está atento a isso, como mencionado pelos participantes P2, P5, P6, P8 e P13., como nos excertos abaixo:

P2.Todos bem capacitados e comprometidos com nossa formação acadêmica; P5.Conhecer melhor os acadêmicos para nos ensinar de uma maneira adequada e para que a nossa formação seja muito boa, para nós termos um conhecimento sobre as atividades que virão; P6.Tem alguns que vão para a aldeia ensinar ao indígena o que ele aprendeu; Como ele quer ser um bom professor, ele quer estudar e ensinar os próximos mesmo dentro da sala de aula; P8.Os professores não indígenas foram ótimos nas suas disciplinas, foram atenciosos, procuraram explicar para nós as disciplinas de maneira clara. P13. O professor não indígena é o que vai nos apontar caminhos desconhecido da área do conhecimento, sendo seu papel fundamental para minha formação acadêmica

\section{Dimensão 4: Crescimento pessoal e profissional}

O crescimento pessoal e profissional foram dois aspectos relevantes relatados pelos participantes P3, P4, P5, P6, P7, P9, P10, P11 e P13. Uma educação intercultural, além de contribuir com o projeto societário de cada povo indígena, também é motivo de elevação do nível cultural e formação de quadros para atuar nas escolas da aldeia. Desta forma, o projeto coletivo permite o crescimento pessoal e profissional das pessoas da aldeia que procuram a educação formal, como destacamos a seguir:

P3. O seu papel possa a ser de pura clareza e ser um bom professor para administrar em uma comunidade indígena; P4.Estamos iniciando nossa vida acadêmica com os professores não indígenas, porque temos que cumprir, como acadêmicos, as normas obrigatórias que são exigidas pela instituição; P5 Que o professor possa conhecer melhor os professores acadêmicos para nos ensinar de uma maneira adequada e para que a nossa formação seja muito boa; P5.Para nós termos um conhecimento sobre as atividades que virão; P10. Espero um dia poder ser igual a eles, ser professor acadêmico, poder ajudar principalmente os povos indígenas; P6.Os professores não indígenas são muito interessados de fazer especialização, mestrado, doutorado. E sempre crescendo no estudo, em várias funções e várias disciplinas; P6.0 professor não indígena pensa nele mesmo, como em estudar e crescer na vida, já pensando no futuro dele; P7.O professor não indígena quando se forma ele forma para ensinar os brancos com a sabedoria de um kupẽ, com as suas tecnologias e sua formação, para se tornar um bom profissional, para ter um bom emprego; P9.Penso que através desses profissionais é que nos tornamos grandes educadores nas escolas indígenas de nossas comunidades; P11.É muito importante para a formação de um cidadão crítico, que busca o conhecimento dos não indígenas para melhor desempenhar seus trabalhos, buscando seus direitos e 
deveres para futuramente conseguir o respeito da sociedade não indígena; P13.Quando recebo o diploma de uma formação sempre sei que o mérito não é só meu, mas sim do mestre também.

Escolhemos analisar primeiramente a Dimensão Interculturalidade por duas condições de produção do discurso: ser a filosofia que orienta o Curso de Licenciatura Intercultural Indígena do qual os participantes são egressos; e, a adesão dos povos pesquisados a luta por escola diferenciada, intercultural e bilingue (EIB). Nesta Dimensão reunimos os discursos que se aproximam da ideia de diálogo respeitoso entre culturas, entendendo-as, como defende Eagleton (2000), o complexo de valores, costumes, crenças e práticas que constituem a forma de vida de um grupo específico, incluindo todas as capacidades e hábitos adquiridos pelo homem como membro da sociedade e que fazem uma pessoa sentir-se enraizada no grupo.

A história dos participantes foi atravessada pela história de professores pertencentes a uma cultura diferente, formados com um tipo de conhecimento diverso e com formas de ser e viver diferenciadas, que foram chegando, transmitindo seus saberes, participando de atividades nas aldeias, comendo suas comidas, bebendo suas bebidas, conhecendo suas tradições e, em contrapartida, depois de 4 anos de convivência, os indígenas estavam graduados, e os professores que conviveram com eles foram ensinar em outras paragens e, assim, conhecer outras culturas.

A relação entre os participantes e os professores não se deu, no entanto, sem os tensionamentos comuns nas relações entre culturas, a fala de P3 é ilustrativa dessa tensão. A interculturalidade não pressupõe a harmonização das relações, vez que essa se dá entre humanos, mas volver o olhar para o respeito ao outro e a sua forma de ser e viver, como afirma Fleury (2003, p. 31),

Tal olhar nos coloca face a face com o estranho, com a diferença, com o desconhecido, que não pode ser reconhecido nem apropriado, mas apenas conhecido na sua especificidade diferenciadora. Não se trata de reduzir o outro ao que nós pensamos ou queremos dele. Não se trata de assimilá-lo a nós mesmos, excluindo sua diferença. Trata-se de abrir o olhar ao estranhamento, ao deslocamento do conhecido para o desconhecido, que não é só o outro sujeito com quem interagimos socialmente, mas também o outro que habita em nós mesmos.

Hall (2006) salienta que estas sociedades têm estado sempre abertas às influências culturais ocidentais. Os povos indígenas participantes, pelas características da sociedade global, têm conexões não só com professores do Curso, mais com diversos elementos da cultura ocidental e com modernas tecnologias de comunicação. Hall (op. cit) alerta que a ideia de que esses são lugares fechados ao contato, etnicamente puros e culturalmente tradicionais é uma fantasia ocidental sobre alteridade. 
Cuche (1999) indica que a interculturalidade é uma construção que se inscreve na história e, mais precisamente, na história das relações dos grupos sociais entre si. O contato vem em primeiro lugar, historicamente, em seguida, há o jogo de distinção que produz as diferenças culturais. Cada coletividade, no interior de uma situação dada, pode ter a tentação de defender sua especificidade, fazendo um esforço através de diversos artifícios para convencer (e se convencer) que sua cultura é original e lhe pertence. A proposta pedagógica do Curso de Licenciatura Intercultural é que esse encontro aconteça com profundo respeito, sem hierarquia cultural e consubstanciado no respeito e valorização das pessoas e dos grupos.

Dos discursos depreende-se que o contato com o professor não indígena foi promissor para o indígena, tanto que o Participante P4 defende que, mesmo formado para assumir a educação escolar indígena, ainda tem necessidade dos professores não indígenas acompanharem as ações educativas nas aldeias, para que a interculturalidade continue a acontecer.

No entanto, há que se considerar que a interculturalidade pugnada pelo $\mathrm{Ml}$ diz respeito aos conhecimentos científicos e culturais, que devem ser trabalhados na escola indígena pelo professor indígena. De acordo com a SECAD/MEC (2007), o perfil profissional a ser buscado na formação dos professores indígenas é o de um ator social que aja nas dimensões social, política, cultural e educativa. Apresenta-se relevante a mediação intercultural entre sua comunidade e agentes da sociedade nacional; a organização de pesquisas para fundamentar sua prática pedagógica que valoriza os saberes indígenas; a associação da escola com os projetos societários e identitários de suas comunidades; a reflexão contínua do papel da escola no contexto interétnico vivido por sua comunidade e o compromisso em transformar a escola em espaço de diálogo intercultural e difusão do conhecimento sobre os direitos indígenas.

Os participantes P1, P2 e P12 indicam que a interculturalidade foi uma via de mão dupla, em que houve aprendizado simultâneo das partes, apesar do não indígena estar na posição do professor. As trocas culturais foram intensas durante o Curso, muitas disciplinas são realizadas dentro da aldeia e mobilizam a cultura dos povos indígenas, assim não há ensino, e sim processos de aprendizagem, que se deslocam nas duas direções. Diversos estudos se desenvolvem nessa mesma perspectiva, como os de Howard (2002) entre os indígenas WaiWai, que demonstram que o contato com o indígena é importante no processo de "humanização" do não indígena, em seu crescimento cultural e intelectual.

Nessa Dimensão, separamos no discurso de P8 um trecho que julgamos interessante analisar em separado: "Os professores não indígenas não sabem sobre a nossa vida social e as nossas culturas tradicionais, pois os mesmos podiam se aprofundar mais em suas 
disciplinas". A primeira impressão é que este discurso se coloca contrariamente aos dos demais participantes, no entanto, na sequência da fala, analisada em outra Dimensão, o participante exprime que "todos" os professores não indígenas foram ótimos.

A análise do discurso acima se desloca para uma situação exterior ao discurso, a forma de organização do curso, com disciplinas condensadas, em períodos que não ultrapassam 15 dias dificulta um mergulho mais aprofundado na cultura do indígena-aluno. Outra variável é que a cultura de um povo só tem sentido para este povo. Geertz (2008), acredita que o homem é um animal amarrado a teias de significados que ele mesmo teceu e a cultura são as teias e a sua análise, como uma ciência interpretativa, à procura do significado. O não indígena não está amarrado a mesma teia de significados que o indígena, portanto, por mais respeitosa que seja a relação entre estes, o tensionamento é inevitável, mesmo que não manifestado explicitamente pelas partes.

As diferenças culturais, no entanto, não são obstáculos para a interculturalidade. Freire (2004) nos ensina que a solidariedade social e política de que precisamos para construir uma sociedade melhor, em que podemos ser mais nós mesmos, tem na formação democrática uma prática de real importância e a aprendizagem de um sujeito é incompatível com o elitismo autoritário dos que se pensam donos da verdade e do saber.

Na segunda Dimensão agrupamos os discursos que apontam para a ideia que o resultado da interação entre os indígenas e professores não indígenas resultou para os primeiros na construção de novos saberes. Neste ponto, o discurso da maioria dos participantes se combina quanto a importância do professor não indígena na aquisição dos saberes científicos da sociedade nacional para fortalecer o projeto social de sua comunidade. No Referencial Curricular Nacional para a Formação de Professores Indígenas (MEC, 2002), um dos objetivos da formação intercultural do professor é contribuir para que se efetive o projeto de autonomia dos povos indígenas a partir de seus projetos históricos, desenvolvendo novas estratégias de sobrevivência física, linguística e cultural.

O participante P12 afirma que a presença do professor não indígena é importante para a formação de um cidadão crítico, que busca o conhecimento dos não indígenas para melhor desempenhar seus trabalhos, buscando seus direitos e deveres para futuramente conseguir o respeito da sociedade não indígena.

Um dos objetivos do Curso é de que o indígena se empodere dos conhecimentos científicos da sociedade nacional, da cultura letrada e práticas docentes, para que possam "tornar-se" professores nas escolas indígenas. O Curso possibilita o acesso aos dois tipos de conhecimento, respeitando a um e a outro, em dialogo de saberes que propicie ao indígena a aquisição de conhecimentos teórico/técnicos, que lhes reforce a luta pela preservação de sua identidade étnica e pelos direitos garantidos nos marcos legais.

C ETD- Educação Temática Digital Campinas, SP

v.20 n.4

p. $1036-1058$ out./dez. 2018 
Esta demarcação de interculturalidade se diferencia das formas anteriores de pensar a relação indigena/não indigena, que considerava $o$ indígena como sujeito com necessecidade de tutelamento. Walsh $(2003,2006)$ aponta na direção da construção de distintas formar de pensar e agir como práxis política que rompa com o institucionalizado.

Os participantes P2, P9 e P12, ao afirmarem que os conhecimentos recebidos os despertaram para a realidade do mundo, trazem para a discussão a questão da formação crítica e do compromisso do professor não indígena com esta formação. Freire (1979) nos lembra que ao nos aproximarmos da natureza do ser que é capaz de se comprometer, estaremos nos aproximando da essência do ato comprometido e que a primeira condição para que um ser possa assumir um ato comprometido está em ser capaz de agir e refletir.

Os discursos revelam sensação de agradecimento aos professores não indígenas. É percebível que a relação entre estes e os indígenas excederam ao ato do somente ensinar. Os participantes afirmam que o não indígena também aprendeu com seus conhecimentos e, tendo consciência do estar no mundo indígena, convivendo com sua cultura, procurou respeitá-la.

$\mathrm{Na}$ terceira Dimensão, transmissão de saberes, agrupamos os discursos que valorizam o papel do professor não indígena na aquisição de saberes da "cultura nacional" pelo indígena e os ajuda a construir competências para "tornar-se" professor indígena e assim contribuir com o projeto societário de seu povo.

Os discursos de P2 "Todos bem capacitados e comprometidos com nossa formação acadêmica", e de P13 "o professor não indígena é o que vai nos apontar caminhos desconhecidos da área do conhecimento, sendo seu papel fundamental para minha formação acadêmica", são representativos. Como nos lembra Freire (2004), a segurança que move a autoridade docente implica na sua competência profissional e o professor que não leve a sério sua formação, que não estuda, que não se esforça para estar à altura de sua tarefa não tem força moral para coordenar as atividades de sua classe, pois a boniteza da prática docente se compõe do anseio vivo de competência do docente e dos discentes e de seu sonho ético.

$\mathrm{Na}$ educação intercultural, a boniteza reside em que os conteúdos de formação sejam transmitidos de forma crítica, responsável, respeitando o saber do outro, dialogando, jamais diminuindo uma cultura em detrimento da outra. Desta forma é construída a educação para a liberdade, para a autonomia do ser do educando que também será educador em sua aldeia. Assim se criam laços de cumplicidade e solidariedade docente, se mobilizam sonhos, ou, usando um termo de Walsh (2006) se decolonializa a educação escolar indígena.

Na quarta Dimensão, crescimento pessoal e profissional, agrupamos os discursos ligados a ideia de que o curso, para além do contributo ao projeto societário dos povos (C) ETD-Educação Temática Digital Campinas, SP $\quad$ v.20 $\quad$ n.4 $\quad$ p.1036-1058 out./dez. 2018 
indígenas, colaborou no crescimento dos graduados enquanto pessoas, seja para o trabalho escolar ou para assumir funções sociopolíticas junto ao seu povo.

Tomamos como ilustração o discurso de P10. "Espero um dia poder ser igual a eles, ser professor acadêmico, poder ajudar principalmente os povos indígenas", que mostra a preocupação com a situação indígena que extrapola a educação escolar. Esta questão tem sido alvo de outros estudos, Luciano (2011) analisou o fenômeno sócio histórico da corrida dos povos indígenas do Rio Negro à escola e a universidade com o objetivo de identificar o lugar que a escola e o mundo moderno ocupam no imaginário dos povos indígenas do Alto Rio Negro, a partir do qual projetam e constroem o seu futuro. A pesquisa de Luciano quis saber quais funções os jovens indígenas do Alto Rio Negro assumiriam nas aldeias ao voltar de seus cursos de formação superior, sem esquecer que os povos indígenas, como qualquer outra sociedade humana, possuem capacidade permanente de superação, em busca de melhores condições de vida, em termos de aperfeiçoamento de seus modos de vida.

Não podemos descolar a melhoria coletiva do crescimento individual, da necessidade de imprimir no processo formativo a capacidade dos sujeitos que irão conduzi-lo. A educação indígena não pode prescindir de, usando um termo de Freire (1979) "trabalhadores sociais" em permanente qualificação e mudança, sujeitos que, ao melhorarem sua formação pessoal, melhoram a formação do grupo. Freire (op. cit) salienta que o trabalhador social que atua numa realidade, a qual, mudando, permanece para mudar novamente, precisa saber que, como homem, somente pode entender ou explicar a si mesmo como um ser em relação com esta realidade; que seu quefazer nesta realidade se dá com outros homens, tão condicionados como ele pela realidade dialeticamente permanente e mutável.

\section{CONSIDERAÇÕES FINAIS}

Marx (2002) afirmava que embora se revele como indivíduo particular, o homem é igualmente a totalidade, a totalidade ideal, a existência subjetiva da sociedade como pensada e sentida. Quando o indígena procura a formação superior, ele não o faz na perspectiva de melhorar somente a si, mais de melhorar o grupo e contribuir com o projeto societário de sua comunidade. A educação intercultural indígena tem esse sentido de educação para a cidadania, instrumento de luta por direitos, negação das formas heterônomas de impor um saber sobre outro, de diálogo construtivo e respeitoso entre as diferentes culturas.

Ao perguntamos ao indígena o que ele pensa sobre o papel do professor não indígena em sua formação, nos foi possível chegar as seguintes conclusões: 
a) Dadas as mesmas condições de produção, excetuando as individualidades, os discursos caminharam no sentido de valorizar o papel do professor não indígena em sua formação, não sem tensões de ordem cultural e pragmática, pois os modos de fazer são diferentes

b) A intenção inicial era produzir sentido a fala em uma comunidade de participantes em que a linguagem não está reduzida a língua. Os povos participantes, além de bilingues, mobilizam variados recursos de comunicação em danças, rituais e pinturas corporais. Para isso imperou a necessidade de mobilizarmos recursos teóricos de análise que extrapolasse o dito e interligasse os discursos com as condições para a sua produção, justificando a escolha pela AD. Ferreira (2010), afirma que a AD, sob a perspectiva de Michel Pêcheux, soube dar um caráter revolucionário ao modo como abordou o papel da linguagem, dando a ela um traço fundacional na constituição do sujeito e do sentido.

c) Apesar dos tensionamentos e estranhamentos originários das relações entre humanos de culturas diferentes, o discurso dos participantes se projeta no sentido de que a relação com o docente não indígena se baseou no diálogo entre saberes e de reconhecimento do direito a diferença;

d) A relação com os docentes do Curso e com os saberes por eles transmitidos Ihes trouxe a possibilidade de contribuir com o projeto societário de suas aldeias melhorando os processos educativos escolares.

e) O processo de produção do discurso, definido por Pêcheux (2014) como o conjunto de mecanismos formais que produzem um discurso do tipo dado e em circunstâncias dadas, propiciou aos participantes extrapolarem o objeto da questão a eles formulada e avançarem para discutir temas tais como interculturalidade e aquisição de saberes.

f) O grupo pesquisado, por sua história de lutas, conquistas, reveses, foi capaz de construir um sentido novo na relação indígena-não indígena a medida que foi confrontado com não indígenas que veem esta relação e a educação indígena de maneira diferente daquela construída historicamente pelo colonizador e seguintes. Orlandi (1999) nos fala que o sujeito se submete à lingua(gem) mergulhado em sua experiência de mundo e determinado pela injunção a dar sentido, a significar(se), em um gesto, um movimento sócio historicamente situado em que se reflete sua interpelação pela ideologia.

Os resultados permitem concluir pela plausibilidade do uso da $A D$ em pesquisas fora do eixo linguagem-psicologia; que o pesquisador precisa redobrar atenção aos interdiscursos e; as condições de produção do discurso devem ser analisadas antes da análise do discurso propriamente dita, para que fique claro de onde, como e em que condições o sujeito discursa; que o Curso de Licenciatura Intercultural propiciou aos 
indígenas o acesso aos conhecimentos científico-culturais do não indígena, resultando em sentimento de reconhecimento e agradecimento pela contribuição destes a sua formação.

\section{REFERÊNCIAS}

ACHARD, Pierre et al. Papel da memória. Tradução e Introdução José Horta Nunes. Campinas, SP: Pontes, 1999.

BAUMAN, Zygmunt. $O$ mal-estar da pós-modernidade. Tradução de Mauro Gama e Claudia Martinelli Gama. Rio de Janeiro: Jorge Zahar, 1998.

BERGAMASCHI, Maria Aparecida. Nhenbo'e: enquanto o encanto permanece! Processos e práticas de escolarização nas aldeias Guarani. 2005. 272 f. Tese (Doutorado em Educação) Faculdade de Educação, Universidade Federal do Rio Grande do Sul, Porto Alegre, 2005.

BRASIL, Congresso Nacional. Constituição da República Federativa do Brasil. In: Vade Mecun Saraiva. 25.ed. São Paulo: Saraiva, 2018.

BRASIL. Lei de diretrizes e bases da educação nacional: lei no 9.394, de 20 de dezembro de 1996, que estabelece as diretrizes e bases da educação nacional. 11 ed. Brasília: Câmara dos Deputados, Coordenação Edições Câmara, 2015. (Série legislação; no 159)

BRASIL, MEC. Referencial curricular nacional para as escolas indígenas Brasília: MEC/SEF, 1998.

BRASIL, MEC. Referencial curricular nacional para a formação de professores indígenas Brasília: MEC/SEF/CAEI, 2002.

CÂNCIO, Raimundo Nonato de Pádua. Para além da aldeia e da escola: um estudo decolonial de aquisição da língua portuguesa pelos indígenas wai-wai da aldeia Mapuera, Amazônia brasileira. 275 f. Tese (Doutorado em Educação) - Programa de Pós-Graduação em Educação, Universidade Federal do Pará, Belém, 2017.

CANDAU, Vera Maria Ferrão; RUSSO, Kelly. Interculturalidade e educação na América Latina: uma construção plural, original e complexa. Rev. Diálogo Educ., Curitiba, v. 10, n. 29, p. 151169, jan./abr. 2010

CANDAU, V. M. Cotidiano escolar e cultura (s): encontros e desencontros. In: CANDAU, V. M. Reinventar a escola. Petrópolis, RJ: Vozes, 2002.

COELHO, Ana Cely de Sousa; SILVA, messias furtado da. Experiência pedagógica de professores karaywa na aldeia indígena Mapuera, Oriximiná-Pa. Revista Exitus, Santarém/PA, v. 8, n.2, p. 163 - 188, maio/ago. 2018.

CUCHE, Denys. A noção de cultura nas ciências sociais. Tradução de Viviane Ribeiro. Bauru/SP: Fim de Século, 1999.

EAGLETON, Terry. A ideia de cultura. Tradução de Sofia Rodrigues. Lisboa: Temas e Debates Atividades, 2000. 
FERREIRA, Maria Cristina Leandro. Análise do discurso e suas interfaces: o lugar do sujeito na trama do discurso. Organon. Revista do Instituto de Letras da Universidade Federal do Rio Grande do Sul. v. 24, n.48, 2010.

FLEURI, Reinaldo Matias. Intercultura e Educação. Revista Brasileira de Educação, n.23, maio/jun./jul./ago. 2003.

FREIRE, Paulo. Pedagogia da autonomia: saberes necessários a prática educativa. 29 ed. São Paulo: Paz e Terra, 2004.

FREIRE, Paulo. Educação e mudança. 12 ed. Paz e Terra. Rio de Janeiro, 1979.

GEERTZ, Clifford. A interpretação das culturas. Rio de Janeiro: LTC, 2008.

HALL, Stuart. A identidade cultural na pós-modernidade. Tradução Tomaz Tadeu da Silva e Guaracira Lopes Louro. 11.ed. Rio de Janeiro: DP\&A, 2006.

HOWARD, Catherine V. A domesticação das mercadorias: estratégias WaiWai. In ALBERT, Bruce. e BARROS, Alcida Rita. Pacificando o branco: cosmologias do contato no norteamazônico. São Paulo: Unesp, 2002.

ISA. Enciclopédia dos Povos Indígenas no Brasil. Disponível em: http://pib.socioambiental.org/pt/povo/gaviao-parkateje/515 Acesso em: 12 de jan. de 2016.

KOPENAWA, Davi; ALBERT, Bruce. A queda do céu: palavras de um xamã yanomami. Tradução Beatriz Perrone-Moisés. São Paulo: Companhia das Letras, 2015.

LUCIANO, Gersen dos Santos. 0 índio brasileiro: o que você precisa saber sobre os povos indígenas no Brasil de hoje. Brasília, DF: Ministério da Educação, Secretaria de Educação Continuada, Alfabetização e Diversidade; LACED/Museu Nacional, 2006.

LUCIANO, Gersen dos Santos. Educação para o manejo e domesticação do mundo: entre a escola ideal e a escola real: os dilemas da educação escolar indígena no alto Rio Negro. Tese (Doutorado em Antropologia) - Instituto de Ciências Sociais, Universidade de Brasília, Brasília, DF: 2011.

MARX, Karl. Manuscritos econômico-filosóficos. São Paulo: Martin Claret. 2002.

ORLANDI, Eni P. Análise de discurso: princípios e procedimentos. Campinas, SP: Pontes, 2001.

ORLANDI, Eni P. Michel Pêcheux e a Análise do Discurso. Revista Estudos da Linguagem, Vitória da Conquista, n.1, p. 9-13, jun./2005.

ORLANDI, Eni P. Do sujeito na história e no simbólico. In LABEURB. Contextos epistemológicos da análise do discurso. Campinas: Laboratório de Estudos Urbanos da UNICAMP, 1999. Série Escritos. v. 4. 
PALADINO, Mariana. Estudar e experimentar na cidade: trajetórias sociais, escolarização e experiência urbana entre "jovens" indígenas Ticuna, Amazonas. 2006. Tese (Doutorado em Antropologia Social) - Museu Nacional, Universidade Federal do Rio de Janeiro, Rio de Janeiro, 2006.

PALADINO, Mariana; ALMEIDA, Nina Paiva. Entre a diversidade e a desigualdade: uma análise das políticas públicas para a educação escolar indígena no Brasil dos governos Lula. Rio de Janeiro: Contra Capa; LACED/Museu Nacional/UFRJ, 2012.

PÊCHEUX, Michel. Semântica e discurso: uma crítica à afirmação do obvio. Tradução Eni Pulcinelli Orlandi et al. 3 ed. Campinas, SP: UNICAMP, 1997 (Coleção Repertórios)

PÊCHEUX, Michel. Análise Automática do Discurso. In: GADET, Françoise. e HAK, Tony. (Org.). Por uma análise automática do discurso: uma introdução a obra de Michel Pêcheux. Tradução de Bethania S. Mariani. 5 ed. Campinas, SP: Unicamp, 2014.

PÊCHEUX, Michel; FUCHS, Catherine. A propósito da análise automática do discurso: atualização e perspectivas (1975). In: GADET, Françoise. e HAK, Tony. (Org.). Por uma análise automática do discurso: uma introdução a obra de Michel Pêcheux. Tradução de Bethania S. Mariani. 5 ed. Campinas, SP: Editora da Unicamp, 2014.

PONCE, Anibal. Educação e luta de classes. 24 ed. São Paulo: Cortez, 2015.

RIKPARTI, Karini Goreth. Pyt Mē Kaxêre e o ensino de história na escola indígena. 2016. Trabalho de Conclusão de Curso (Graduação em Licenciatura Intercultural Indígena) Universidade do Estado do Pará, Marabá, 2016.

RODRIGUES, Aryon Dall'Igna. Línguas indígenas brasileiras. Brasília, DF: Laboratório de Línguas Indígenas da UnB, 2013.

SANTOS, Boaventura de Sousa. A universidade no século XXI: para uma reforma democrática e emancipatória da universidade. 3 ed. São Paulo: Cortez, 2011.

SAUSSURE, Ferdinand de. Curso de Linguística Geral. Organizado por Charles Bally e Albert Riedlinger. Tradução de Antônio Chelini, José Paulo Paes e Izidoro Blikstein. 27 ed. São Paulo: Cultrix, 2006.

SECAD. Educação Escolar Indígena: diversidade sociocultural indígena ressignificando a escola. Cadernos SECAD, v.3 Brasília, DF: Secad/MEC, 2007.

SURUÍ, Warykatu. Produção e aplicação de cartilha em escola indígena: mamíferos da cultura Aikewara. 2016. Trabalho de Conclusão de Curso (Graduação em Licenciatura Intercultural Indígena) - Universidade do Estado do Pará, Marabá, 2016.

UNIVERSIDADE DO ESTADO DO PARÁ. Projeto Pedagógico do Curso de Licenciatura Intercultural Indígena. Belém,PA: UEPA, 2012.

WALSH. Catherine. Interculturalidad, descolonizacion del estado y del conocimiento. Buenos Aires: Del Signo. 2006. 
WALSH, Catherine. Interculturalidad, plurinacionalidad y decolonialidad: las insurgencias político-epistémicas de refundar el Estado. Tabula Rasa, Bogotá, Colômbia, n.9, p.131-152, jul./dic.2008.

WALSH. Catherine. Estudios culturales latnoamericanos: retos desde y sobre la región andina. Quito: Universidad Andina Simón Bolívar/Abya-Yala, 2003.

* Revisão gramatical do texto sob responsabilidade de:

Marciane Costa (Bacharel em Letras)

E-mail: anny nmcosta@yahoo.com 